\title{
Characteristics of avalanching: Kootenay Pass, British Columbia, Canada
}

\author{
D. M. MCCLuNG \\ Departments of Civil Engineering and Geography, University of British Columbia, Vancouver, British Columbia V6T 124, Canada \\ JOHN TWEEDY \\ British Columbia Ministry of Transportation and Highways, Nelson, British Columbia V1L 6B9, Canada
}

\begin{abstract}
Individual variables found to be significant from a correlation analysis are analyzed as a function of probability of avalanching for data from Kootenay Pass, British Columbia. The analysis is compared with a similar study for data from Alta, Utah, U.S.A. The results show that the variable significance is very similar for the two areas. Primary variables include: snowfall rate, weight of new snow, water equivalent of new precipitation, total storm snow and new snow depth. Secondary variables include wind speed and direction, and new-snow density.
\end{abstract}

\section{INTRODUCTION}

Perla (1970) analyzed individual factors thought to be important in avalanche-hazard evaluations using 20 years' of storm data from Alta, Utah, U.S.A. Since then, no similar analysis has been presented for comparison of individual factors from different mountain ranges or climate zones.

In this study, 11 years of records using twice-daily observations are analyzed for measurements at Kootenay Pass, British Columbia, relevant to prediction of avalanche hazard for the highway over Kootenay Pass in southern British Columbia. From the analysis, we show that Kootenay Pass may be classed as a transitional climate zone similar to Alta: midway between maritime and continental. Comparison of our analysis with Perla's shows that both areas have very similar characters with respect to variables important for avalanching. The results lend further support for the variables shown to be important by Perla's study for avalanching of new snow.

\section{KOOTENAY PASS SNOW-GLIMATE TYPE}

Kootenay Pass lies at an elevation of $1775 \mathrm{~m}$ in the southeast corner of British Columbia on a major highway between the towns of Salmo and Creston. The average snowfall is about $1200 \mathrm{~cm}$ and approximately 300 significant avalanches per season (early November-late April) have been recorded. Since the highway opened in 1963, seven avalanche fatalities have been recorded in the pass area, the last being in 1976. Active avalanche control began in 1975 .

According to Armstrong and Armstrong (1987), snow climates may be classed roughly as maritime, transitional or continental according to average air temperatures, average snow depth and new-snow density measured throughout a winter (November-April). Armstrong and Armstrong (1987) provided long-term data from the U.S. averaged over 15 winters to help classify a snow regime.

For Kootenay Pass, over the 11 year period analyzed, the following average values were observed: average snow depth: $185 \mathrm{~cm}$; average air temperature: $-5^{\circ} \mathrm{C}$; average new-snow density: $92 \mathrm{~kg} \mathrm{~m}^{-3}$. For comparison, average values by Armstrong and Armstrong (1987) for a mix of reporting stations for 15 years of records in the U.S. give the values in Table 1. Comparison indicates that Kootenay Pass may be considered closest to a transitional climate if the three indices in Table 1 are used as the classification basis. Perla's (1970) study of southfacing slopes at Alta was also for a transitional climate, so that a comparison for the two areas should show similar results.

Table 1. Character of climate zones in the United States November-April data - 15 years of records (Armstrong and Armstrong, 1987)

\section{Unit Maritime Transitional Continental}

\begin{tabular}{ccccc}
$\begin{array}{c}\text { Average snow } \\
\text { depth }\end{array}$ & $\mathrm{cm}$ & 186 & 170 & 113 \\
$\begin{array}{c}\text { Average air } \\
\text { temperature }\end{array}$ & ${ }^{\circ} \mathrm{C}$ & -1 & -5 & -7 \\
$\begin{array}{r}\text { Average new; } \\
\text { snow density }\end{array}$ & $\mathrm{kg} \mathrm{m}^{-3}$ & 120 & 85 & 70 \\
\hline
\end{tabular}




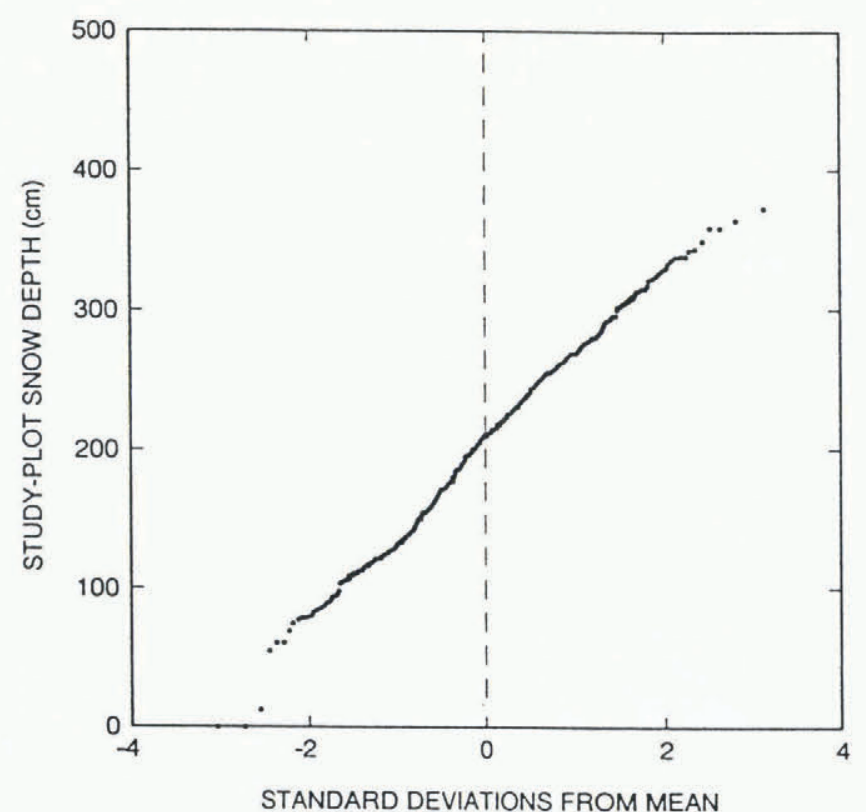

Fig. 1. Probability plot of study-plot snow depth represented as a Gaussian variable. The scale on the abscissa is in standard deviations $(65 \mathrm{~cm})$ from the mean $(205 \mathrm{~cm})$. Data presented are only from time periods when avalanches occurred.

Figure 1 shows snow-depth data measured on days when avalanches occurred over the 11 year period. The normal probability plot in Figure 1 was constructed by rank ordering and sorting the data as a batch. The expected values corresponding to the observations are plotted as a function of their probabilities for a Gaussian distribution by relating the probabilities to standard deviations from the mean (the abscissa in Figure 1). For Figure 1, the mean value is $205 \mathrm{~cm}$ and standard deviation is $65 \mathrm{~cm}$. The mean value is slightly higher than for all days $(185 \mathrm{~cm})$ in the data set, since Figure 1 refers only to periods when avalanches occurred.

\section{DATA GOLLECTION}

Snow, avalanche occurrence and weather data were collected at Kootenay Pass, British Columbia, for 11 winters (1980-81 through 1990-91) by making twicedaily observations: early morning and late afternoon. These data together consist of the approximately 3300 records used in the analysis.

Avalanche occurrences were recorded and grouped with snow and weather data according to the time of occurrence: those recorded between $24 \mathrm{~h}$ midnight and $12 \mathrm{~h}$ noon were grouped with morning observations; the remainder were grouped with afternoon observations. Avalanche occurrences were recorded (regardless of size), if they had potential for affecting the highway and all meeting this condition were used in this study. In addition to the events, the size class on the Canadian scale (see Table 2) was recorded. This allowed calculation of a parameter called the avalanche-activity index (AAI) within each time period: the sum of avalanche sizes observed. The AAI is a simple index of magnitude and frequency of avalanching within a time period. No distinction between wet and dry avalanches is made in the present paper. However, such distinction will be included in a subsequent paper containing a multivariable analysis.

\section{METHOD OF ANALYSIS}

Parameters were analyzed by correlating individual variables with an avalanche-occurrence index. The avalanche-occurrence index is defined as a two-value categorical variable depending on whether avalanches occurred or not during a given time period. Those variables, which significantly correlated with the avalanche activity, were retained and analyzed. Variable retention was based upon the $F$ statistic (and its significance) for each variable. Therefore, retention of variables was defined in a similar way to the procedures used in a step-wise regression analysis (Bovis, 1977; Obled and Good, 1980).

In addition to the significant variables, two further variables were analyzed, even though they had virtually no correlation with avalanche/non-avalanche days. These factors were not analyzed by Perla (1970) but they are similar to variables proposed by Atwater (1954) as possibly significant for avalanche-hazard evaluation.

Many variables were tested for significance as described above (air temperatures and relative humidity are examples) but only those which had significant correlations with the index, as well as surface-moisture content and condition, are presented in the analysis below.

Table 2. Canadian snow-avalanche size-classification system and typical factors

$\begin{array}{cccc}\text { Size Description } & \text { Typical } & \text { Typical } & \text { Typical } \\ & \text { mass } & \text { path } & \text { impact } \\ & & \text { length } & \text { pressures }\end{array}$

1 Relatively harmless $\quad<10 \mathrm{t} \quad 10 \mathrm{~m} \quad 1 \mathrm{kPa}$ to people

$2 \quad$ Could bury, injure $\quad 10^{2} \mathrm{t} \quad 100 \mathrm{~m} \quad 10 \mathrm{kPa}$ or kill a person

3 Could bury a car, $\quad 10^{3} \mathrm{t} \quad 1000 \mathrm{~m} \quad 100 \mathrm{kPa}$ destroy a small building or break a few trees

$4 \quad$ Could destroy a rail- $\quad 10^{4} \mathrm{t} \quad 2000 \mathrm{~m} \quad 500 \mathrm{kPa}$ way car, large truck, several buildings or a forest with an area up to 4 ha $\left(40000 \mathrm{~m}^{2}\right)$

$5 \quad$ Largest snow aval- $\quad 10^{5} \mathrm{t} \quad 3000 \mathrm{~m} \quad 1000 \mathrm{kPa}$ anches known; could destroy a village or a forest of 40 ha 
Following Perla (1970), scatter plots were constructed for each variable and the variables were categorized according to four or five classes by inspection of the scatter plots. Figure 2 depicts a typical scatter plot. All of the variables analyzed are given in Table 3 .

Three levels of avalanche probability were analyzed for each category of each variable. These levels were defined by: (1) the fraction of points for which avalanching occurred in each variable category; (2) the fraction of points for which AAI $\geq 3$ in each variable category; (3) the fraction of points for which AAI $\geq 10$ for each variable category. Only the latter two levels (AAI > 3, AAI > 10) are reported in the results. The segregation into avalanche/non-avalanche days (level (1)) was used to derive the $F$ statistics for variable selection.

\section{RESULTS}

In this section, the results are presented for each variable by variable number (Table 3 ). The points for variables 3 , 4, 6, 7 and 8 are plotted at the middle of the intervals for the variable categories listed in Table 3 . Therefore, the first-plotted point for variable 3 at $5 \mathrm{~cm}$ represents all cases with less than $10 \mathrm{~cm}$ total storm snow and the last point represents all cases with greater than $40 \mathrm{~cm}$ total storm snow. Individual variables are discussed below.

\section{Precipitation type (Fig. 3)}

The trends as a function of precipitation type are too weak to be of use except for the category of freezing rain. No examples of avalanching with mixed rain and snow were present in the data base and therefore that category is not included in Figure 3. Note that probability of avalanching is not zero during periods for which no precipitation is falling. This is due principally to

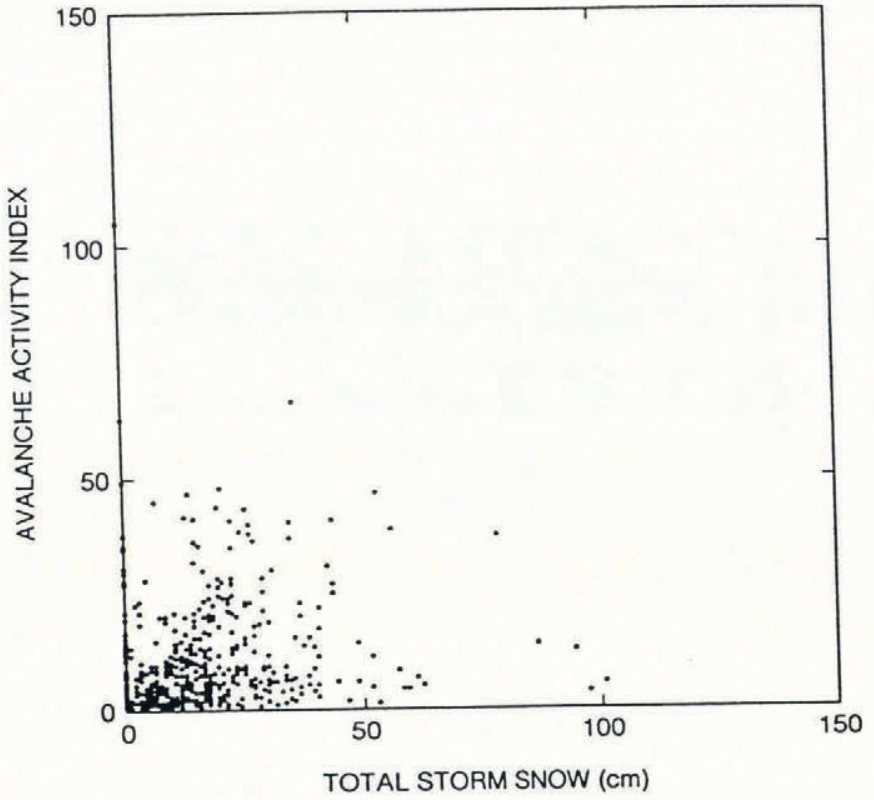

Fig. 2. Scatter plot of avalanche-activity index (AAI) versus total storm snow (cm); see Figure 5 for probability plot constructed from this graph.

avalanche control by explosives but it may also include avalanches which release naturally after a storm or during warm periods.

\section{Snowfall rate (Fig. 4)}

The trends in Figure 4 show that for both AAI $\geq 3$ and AAI $\geq 10$ snowfall rate is an important variable, even though the trend is quite gentle for AAI $\geq 10$ until the snowfall rate exceeds $2 \mathrm{~cm} \mathrm{~h}^{-1}$. For AAI $\geq 3$, the probability is 1.0 for a snowfall rate of $4 \mathrm{~cm} \mathrm{~h}^{-1}$ but, since only one time interval contained this high rate, this point was not plotted.

Table 3. Variables and categories

\begin{tabular}{clll}
\hline $\begin{array}{l}\text { Variable } \\
\text { No. }\end{array}$ & Variable & Category
\end{tabular}

\begin{tabular}{|c|c|c|c|c|c|c|c|}
\hline 1 & Precipitation type & & Zero & Snow & Rain & $\begin{array}{l}\text { Freezing } \\
\text { rain }\end{array}$ & $\begin{array}{l}\text { Mixed } \\
\text { rain-snow }\end{array}$ \\
\hline 2 & Snowfall rate & $\mathrm{cm} \mathrm{h}^{-1}$ & 0 & 1 & 2 & 3 & 4 \\
\hline 3 & Total storm snow & $\mathrm{cm}$ & $<10$ & $10-20$ & $20-30$ & $30-40$ & $>40$ \\
\hline 4 & New-snow depth & $\mathrm{cm}$ & $0-5$ & $5-10$ & $10-15$ & $15-20$ & $>20$ \\
\hline 5 & Surface moisture & & & Dry & Moist & Wet & Very wet \\
\hline 6 & New-snow normal stress & $\mathrm{Pa}$ & $<70$ & $70-140$ & $140-210$ & $210-280$ & $>280$ \\
\hline 7 & $\begin{array}{l}\text { Water-equivalent new } \\
\text { precipitation }\end{array}$ & $\mathrm{mm}$ & $<5$ & $5-10$ & $10-15$ & $15-20$ & $>20$ \\
\hline 8 & New-snow density & $\mathrm{kg} \mathrm{m}^{-3}$ & $<50$ & $50-100$ & $100-150$ & $150-200$ & $>200$ \\
\hline 9 & Wind speed & $\mathrm{m} \mathrm{s}^{-1}$ & Calm & $\begin{array}{l}\text { Light } \\
1-7\end{array}$ & $\begin{array}{l}\text { Moderate } \\
8-11\end{array}$ & $\begin{array}{l}\text { Strong } \\
>11\end{array}$ & \\
\hline 10 & Wind direction & & Calm & $\mathrm{N} \quad \mathrm{NE}$ & E SE & S SW & W NW \\
\hline 11 & Surface-snow condition & & Surface rain & \multirow{2}{*}{\multicolumn{2}{|c|}{$\begin{array}{l}\text { Ice Wind crust } \\
\text { Rain channels }\end{array}$}} & New snow & Other \\
\hline & & & Sun cups & & & Old snow & \\
\hline
\end{tabular}




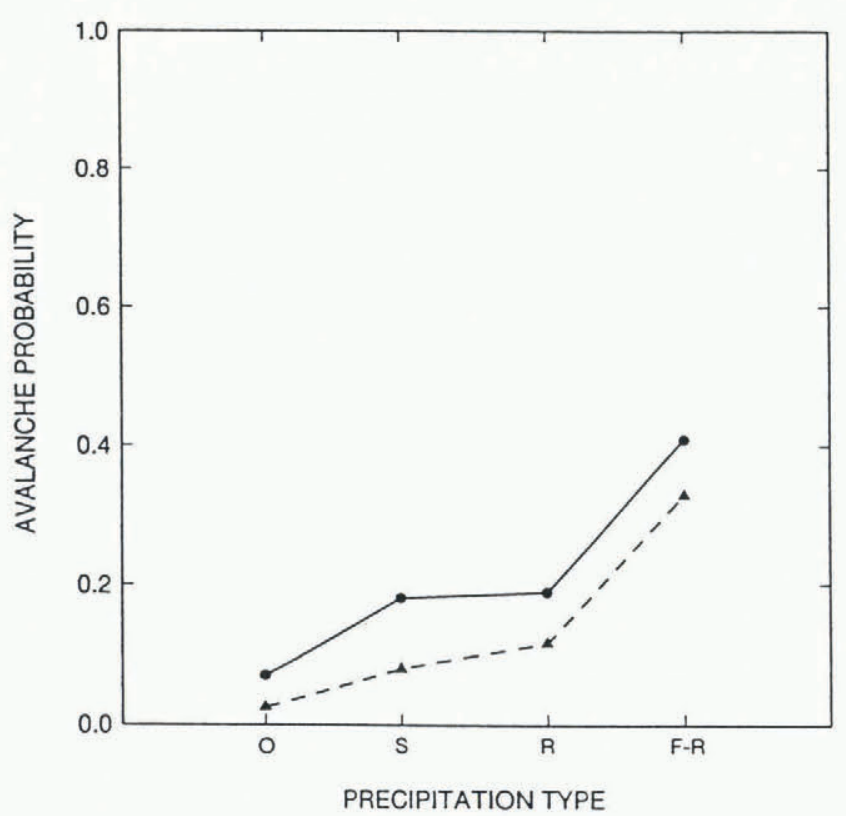

Fig. 3. Avalanche-probability for two levels of avalancheactivity index (AAI) versus precipitation type. $\bullet$ $A A I \geq 3 ; \mathbf{\Delta}-\mathbf{\Delta} A A I \geq 10$. 0- no precipitation; $S-$ snow, $R$-rain, $F-R$ - freezing rain.

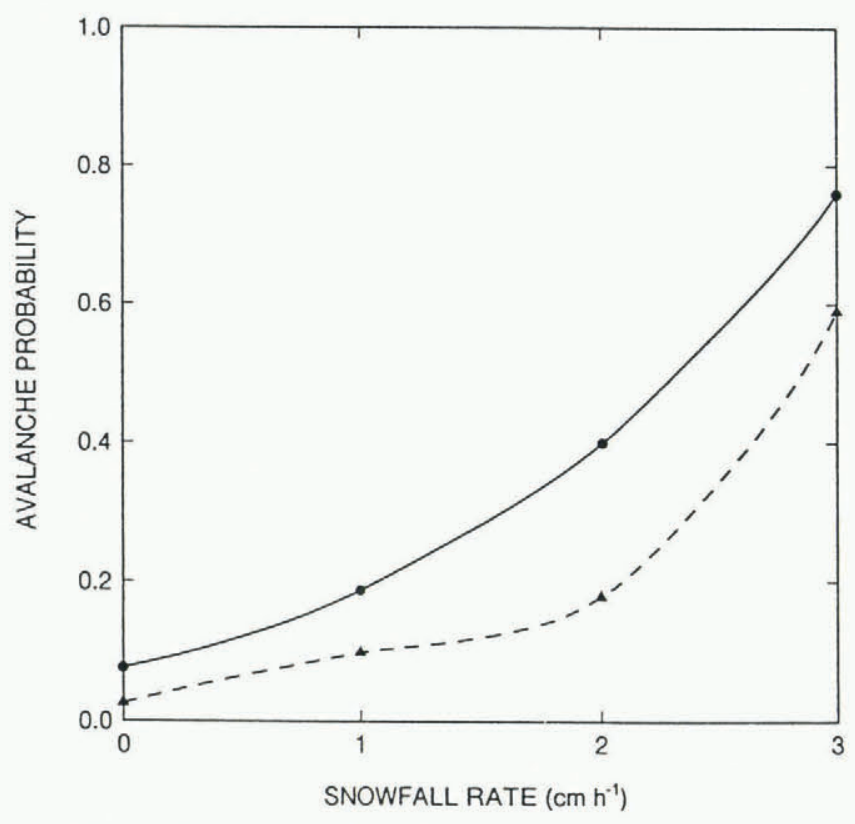

Fig. 4. Similar to Figure 3 with abscissa representing snowfall rate $\left(\mathrm{cm} \mathrm{h}^{-1}\right)$. Data points are midpoints of intervals, in Table 3. $\bullet A A I \geq 3 ; \mathbf{\Delta}-\mathbf{\Delta} A A I \geq 10$.

\section{Total storm snow (Fig. 5)}

Total storm snow is an important variable for both $\mathrm{AAI} \geq 3$ and $\mathrm{AAI} \geq 10$ but the trend is weaker for AAI $\geq 10$ : Perla (1970) defined a trend such as shown for AAI $\geq 10$ as a second-order effect, because of the inflection point between 20 and $40 \mathrm{~cm}$ of total storm snow.

\section{New snow (Fig. 6)}

New snow is a primary variable for both curves in Figure 6 with strong trends. Analysis showed that the overall

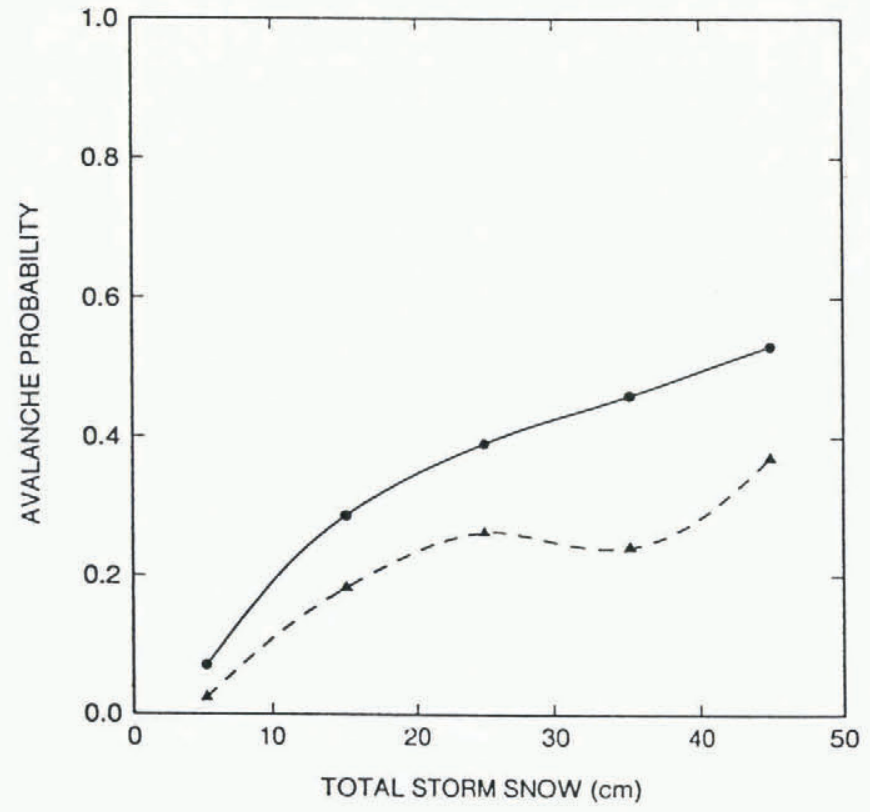

Fig. 5. Probability plot (similar to Figure 3) for the scatter plot of Figure 2. Data points represent mid-points in the intervals given in Table 3. $\bullet A A I \geq 3$; $A A I \geq 10$.

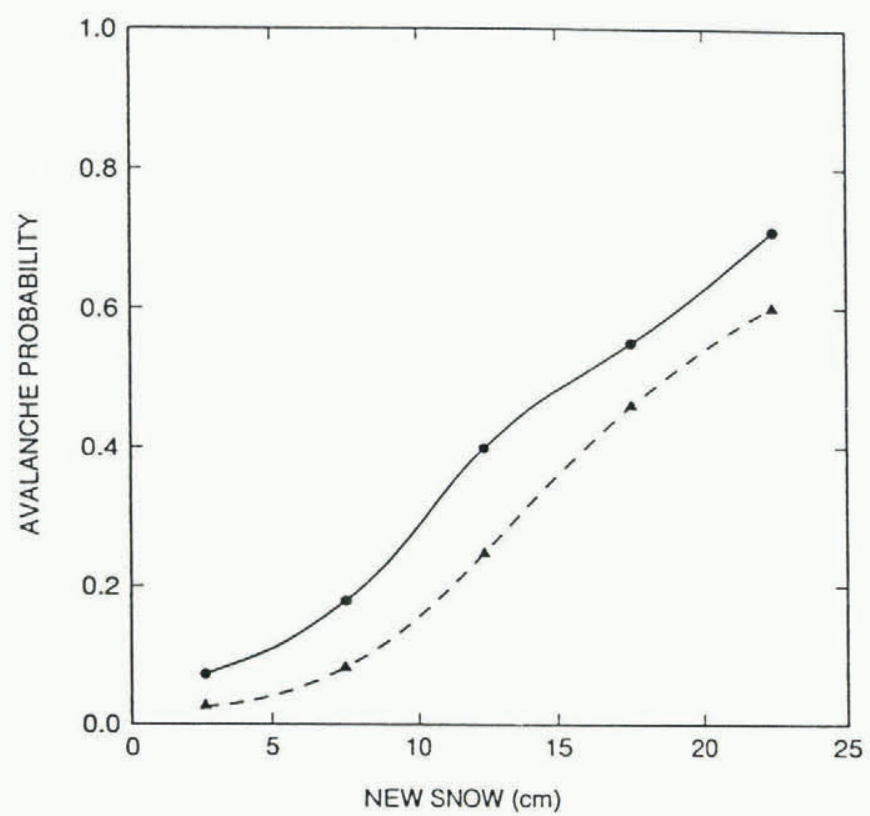

Fig. 6. Probability plots for new-snow depth. Similar to the top of Figure 5. $\bullet A A I \geq 3 ; \mathbf{\Delta}-\mathbf{\Delta} A A I \geq 10$.

probability of avalanching is $11 \%$ for new-snow depths less than $5 \mathrm{~cm}$. This is a result of avalanche control and sluffing activity.

\section{Surface moisture (Fig. 7)}

Moisture content of surface snow was categorized according to the International Classification (Colbeck and others, 1990). No trend is evident except when the surface becomes very wet. No stratification with respect to wet and dry avalanches was introduced in this study. An important characteristic of the weather at Kootenay Pass is that rain may occur at any time during the winter. 


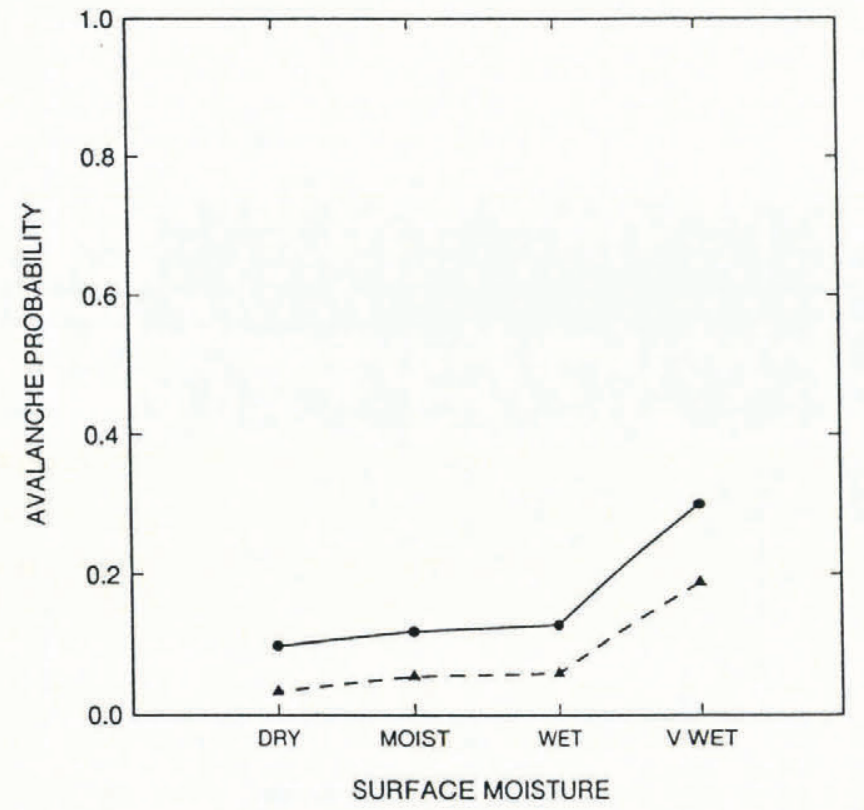

Fig. 7. Probability plots for surface-moisture contents: dry, moist, wet and very wet. No data were obtained for slush at the surface. $\bullet A A I \geq 3 ; \mathbf{\Delta}-\mathbf{\Delta} A A I \geq 10$.

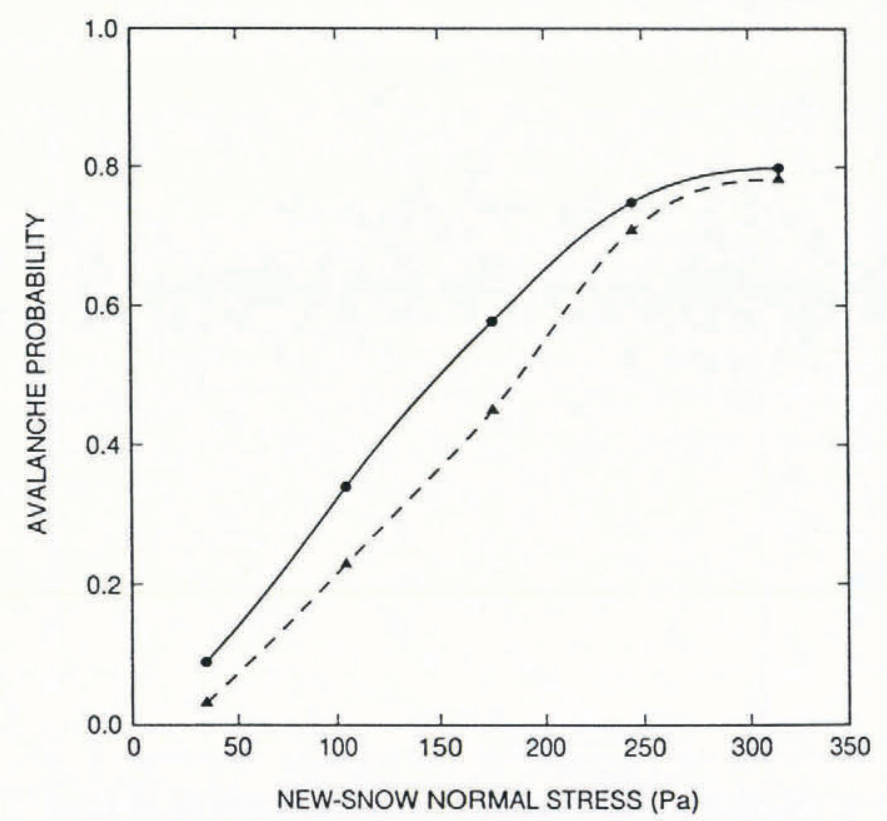

Fig. 8. Avalanche-probability for (vertical) normal stress due to new snow. See Table 3 for interval categories. The values are calculated by dividing the weight of a sample of new snow taken with a cylindrical tube divided by the area of the tube. $\bullet A A I \geq 3 ; \mathbf{\Delta}-\mathbf{\Delta} A A I \geq 10$.

Therefore, splitting the avalanche season into wet and dry avalanche sub-seasons, as done by Perla (1970), Bovis (1977) and Obled and Good (1980), is not desirable. However, the implication from Figure 7 is that when the surface is very wet the probability of avalanching increases significantly for both curves.

\section{New-snow normal stress (Fig. 8)}

Normal stress is calculated as the weight (force $(\mathrm{N})$ ) per unit area of new snow as measured on the new-snow board. Figure 8 shows that it is an important variable for both $\mathrm{AAI} \geq 3$ and $\mathrm{AAI} \geq 10$.

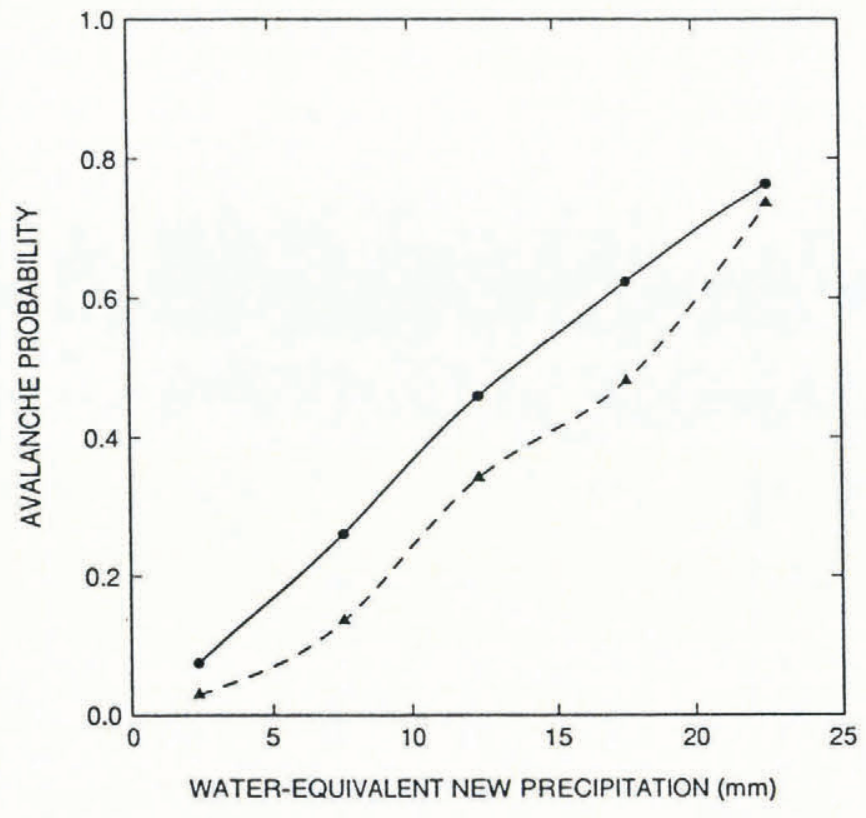

Fig. 9. Avalanche-probability for water-equivalent new precipitation ( $\mathrm{mm})$. See Table 3 for interval categories. $\bullet A A I \geq 3 ; \mathbf{\Delta}-\mathbf{\Delta} A A I \geq 10$.

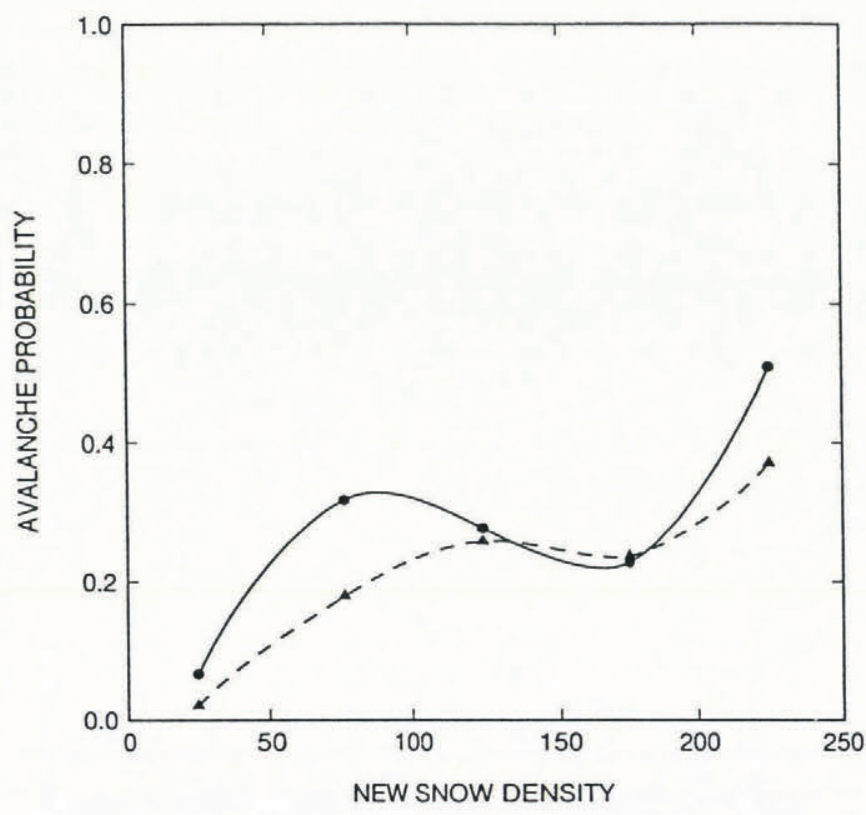

Fig. 10. Avalanche-probability for new-snow density. See Table 3 for interval categories. $A A I \geq 10$.

\section{Water-equivalent new precipitation (Fig. 9)}

Water equivalent of new precipitation is very similar to new-snow normal stress. In this study, water-equivalent new precipitation includes all precipitation from snow or rain. Both curves in Figure 9 represent primary effects.

\section{New-snow density (Fig. 10)}

Oscillatory effects are present for both curves in Figure 10. However, for $\mathrm{AAI} \geq 3$, the trend may be stronger. For Kootenay Pass, the average new-snow density is $92 \mathrm{~kg} \mathrm{~m}^{-3}$. Figure 10 shows the trend is strong for new- 


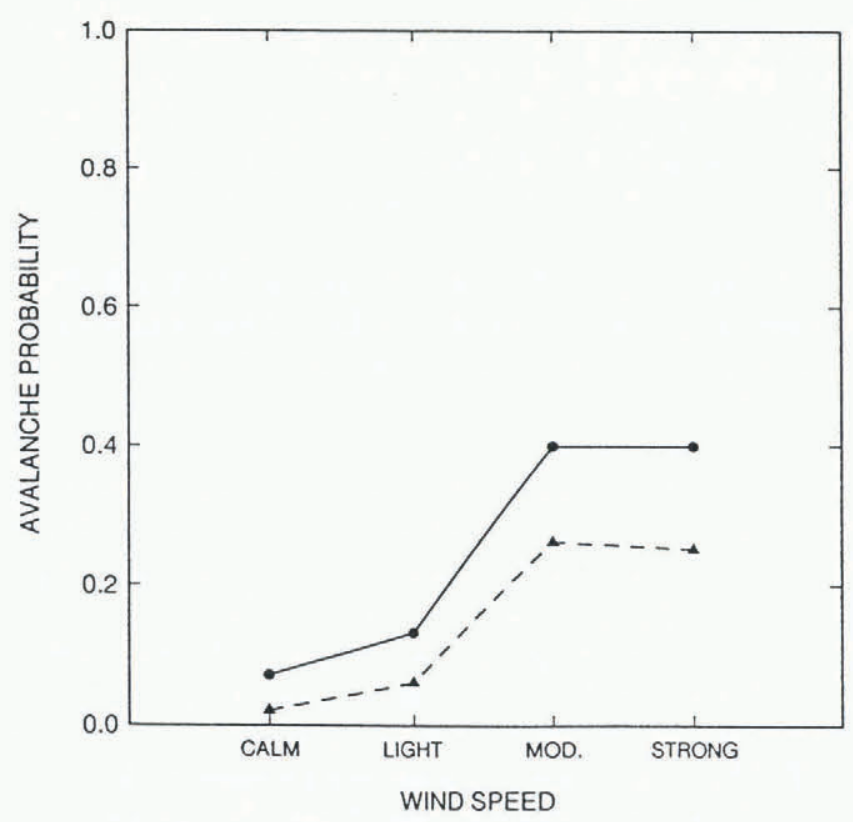

Fig. 11. Avalanche-probability for wind speed. See Table 3 for approximate definitions of light, moderate and strong wind speed. $\bullet A A I \geq 3 ; \mathbf{\Delta}-\mathbf{\Delta} A A I \geq 10$.

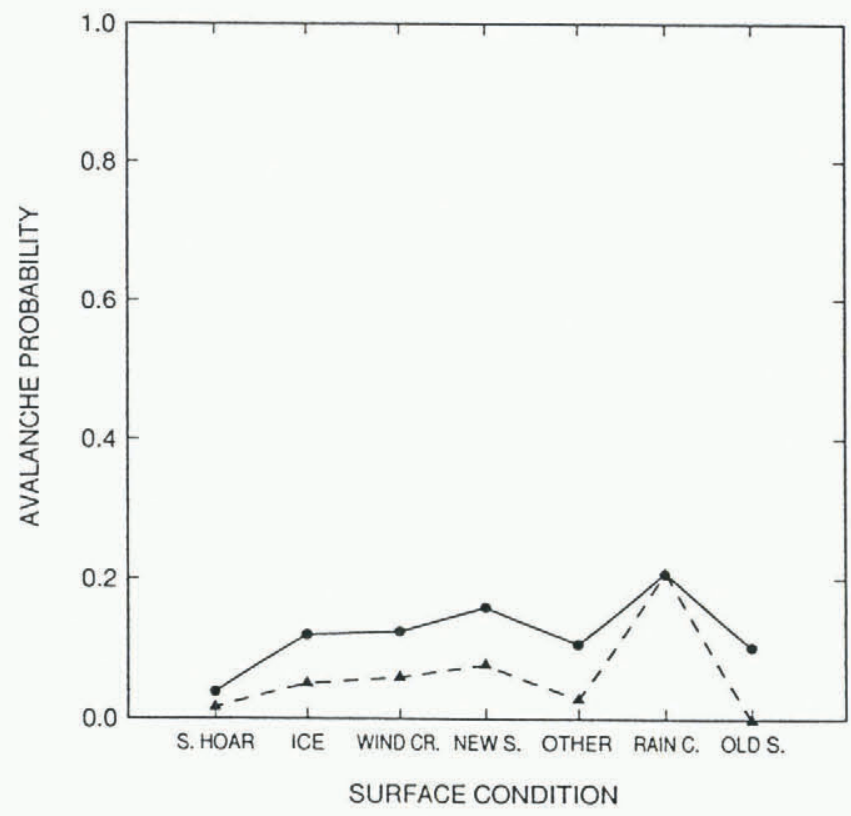

Fig. 12. Avalanche-probability related to surface condition. Categories represented include: surface hoar, ice, wind crust, new snow, other (miscellaneous), rain channels and old snow. $\bullet A A I \geq 3 ; \mathbf{\Delta}-\mathbf{\Delta} A A I \geq 10$.

snow density below the average and for values exceeding $200 \mathrm{~kg} \mathrm{~m}^{-3}$. The latter may represent strong wind effects or wet new snow.

\section{Wind speed (Fig. 11)}

Data represented in Figure 11 show trends for both curves which are important as the wind speed increases from light to moderate. However, for wind speeds beyond moderate, no trend is evident. Conventional interpretation of the relation of wind speed to slab-avalanching is that the wind must be strong enough to wind-pack and transport snow but not so strong that wind-packing

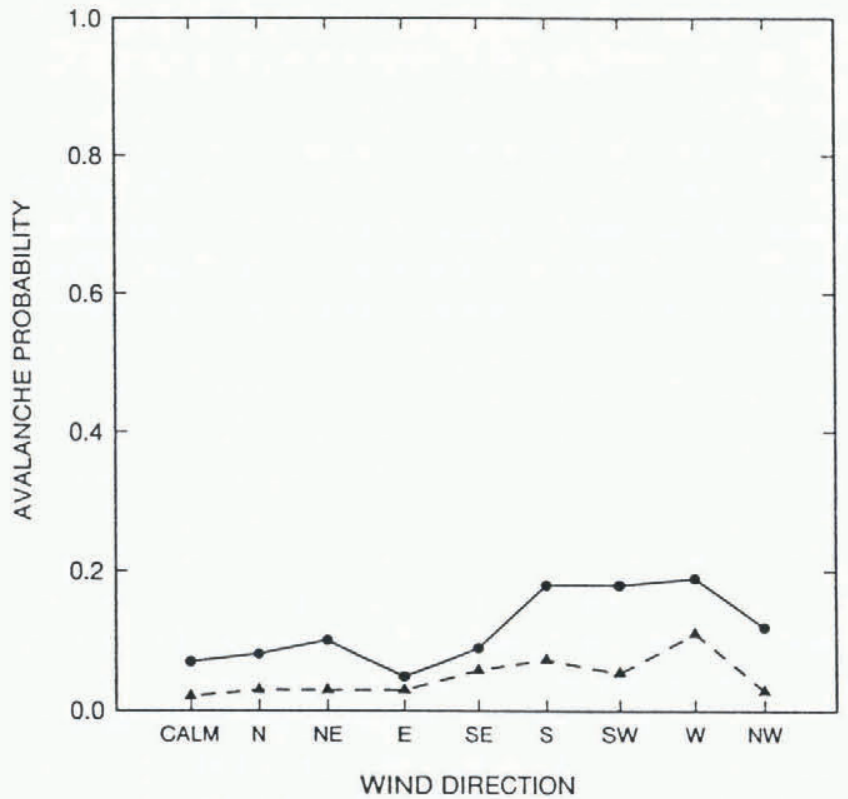

Fig. 13. Avalanche-probability versus wind direction. $A A I \geq 3 ; \mathbf{\Delta}-\mathbf{\Delta} A A I \geq 10$.

creates very stiff, hardened snow to make avalanching less probable. The data in Figure 11 are consistent with these concepts.

\section{Surface condition (Fig. 12)}

The data in Figure 12 do not show significant variations except when rain channels are present at the surface. This effect compares favourably to Figure 7 . It is also interesting to note that, for $\mathrm{AAI} \geq 10$, avalanching is not observed when the surface is old snow. For the present study, $\mathrm{AAI} \geq 10$ generally means a cycle of at least several slab avalanches. It is not surprising, therefore, that $\mathrm{AAI} \geq 10$ is not frequently observed when the surface is composed of old snow.

\section{Wind direction (Fig. 13)}

The data in Figure 13 show a prevalance for avalanching when the wind is in the southerly and westerly directions. This is expected of Kootenay Pass, since the major storm direction is from the west and southerly directions of Kootenay Pass. Not much fundamental significance can be attached to these wind-direction data, since they represent observations at standard times instead of storm averages. Furthermore, Figure 13 may only be indicating the major storm directions.

\section{SUMMARY OF RESULTS}

The study presented represents a simple single-variable analysis of parameters commonly measured by avalanche forecasters. Variables 2, 3, 4, 6, 7, 8, 9 and 10 were selected because they were significant in a correlation analysis. The analysis here confirms this result: most of these variables 2, 3, 4, 6 and 7 have first-order significance with respect to avalanche probability for at least one of 
the two levels of avalanche activity studied (AAI $\geq 3$, AAI $\geq 10$ ). Variables 8,9 and 10 have second-order significance.

Variables 1, 5 and 11 were included with the present study because they are related to conditions at the surface which were included in two of Atwater's (1954) list of ten contributory factors significant for avalanching. However, they were not significant in the correlation analysis. Variable 1 shows no strong trend except when freezing rain occurs. Freezing rain often means that a temperature inversion is in place with possible rain and warm conditions at starting-zone levels. Therefore, the strong trend observed during conditions of freezing rain may indicate a warning for wet-avalanche activity.

Variables 5 and 11 show discernible trends for very wet-surface conditions and rain channels at the surface, and therefore they warn of wet-avalanche activity. Since, in this particular study, no stratification with respect to wet and dry avalanching was introduced, it is not surprising that variables 1,5 and 11 did not appear as significant in the analysis. However, they might appear once wet and dry avalanches are considered under separate analyses. Similarly, air-temperature data (maximum, minimum, present and trends) did not appear as significant in the present analysis, but they might appear if a sub-set of wet-avalanche periods is analyzed.

\section{COMPARISON WITH PREVIOUS WORK}

Perla (1970) has presented a similar study with data from Alta, Utah, based on 20 years of storm records. $\mathrm{He}$ considered only large avalanches (size 3 or larger; Table 2) which released from south-facing slopes and which could affect the Alta Highway and Village. Even though the time record (20years) is nearly twice as long as the present study, the data base he considered is much smaller than that in the present study (approximately 3300 time records). Furthermore, Perla considered only data taken during storm periods, whereas the present study includes all measurement periods including clear-weather periods.

In spite of the differences in data collection, the results of the present study are very similar to those obtained by Perla (1970). The actual probability values are different but two of the primary variables: total storm snow (3) and new-snow depth (4) have very similar probability trends to those in Perla's study. Variable (2) (snowfall rate) shows weak trends until the rate exceeds $2 \mathrm{~cm} \mathrm{~h}^{-1}$. Perla did not analyze snowfall rate. However, his analysis of average precipitation rate did not show strong trends for $\mathrm{AAI} \geq 3$ or $\mathrm{AAI} \geq 10$ and, therefore, there may be some consistency with the present analysis. In addition, wind speed and direction (variables 9 and 10) show secondary effects have trends which are similar to Perla's results.

New-snow density (variable 8) was not analyzed by Perla. The oscillating trends in Figure 10 may indicate some interesting results for the practitioner: the strong trends for new-snow densities rising toward $100 \mathrm{~kg} \mathrm{~m}^{-3}$ are consistent with the expectation that new-snow densities above $50 \mathrm{~kg} \mathrm{~m}^{-3}$ favor slab-avalanche formation, since some strength is needed to form a slab. Similarly, high new-snow densities $\left(>150 \mathrm{~kg} \mathrm{~m}^{-3}\right)$ may indicate dense wet snow or strong wind-packing effects. Both of these possibilities might favor avalanching.

Comparison with the analysis of Perla (1970) may allow some general statements to be made. However, three important points must be kept in mind:

(1) The results are from a univariate analysis; a multivariate analysis will probably reveal important correlations between precipitation variables or wind variables.

(2) The results here are from a general statistical analysis; individual situations may reveal specifics which are important. Therefore, it is possible that any or all of Atwater's ten contributory factors may be relevant given the proper circumstances. One must be guided by physical as well as general analysis results.

(3) The results from this study are by categorizing the variables into intervals (see Table 3 ), which are chosen by inspection of scatter plots to yield 4-5 intervals with a fairly good population of values in an interval. A different choice of intervals may change the results significantly.

\section{ACKNOWLEDGEMENTS}

This research was sponsored by the British Columbia Ministry of Transportation and Highways and National Research Council Canada. The data used in this study result not only from collection at Kootenay Pass but also from the efforts of many people from the Snow Avalanche Section, British Columbia Minstry of Transportation and Highways.

\section{REFERENCES}

Armstrong, R. L. and B. R. Armstrong. 1987. Snow and avalanche climates of the western United States: a comparison of maritime, intermountain and continental conditions. International Association of Hydrological Sciences Publication 162 (Symposium at Davos 1986 Avalanche Formation, Movement and Effects), 281-294.

Atwater, M. M. 1954. Snow avalanches. Sci. Am., 190(1), 26-31.

Bovis, M.J. 1977. Statistical forecasting of snow avalanches, San Juan Mountains, southern Colorado, U.S.A. 7. Glaciol., 18(78), 87-99.

Colbeck, S. C. and 7 others. 1990. The international classification for seasonal snow on the ground. World Data Center A for Glaciology, Boulder, Colorado, International Association of Scientific Hydrology.

Obled, C. and W. Good. 1980. Recent developments of avalanche forecasting by discriminant analysis techniques: a methodological review and some applications to the Parsenn area (Davos, Switzerland). F. Glaciol., 25(92), 315-346.

Perla, R. I. 1970. On contributory factors in avalanche hazard evaluation. Can. Geotech. F., 7(4), 414-419.

The accuracy of references in the text and in this list is the responsibility of the authors, to whom queries should be addressed. 